\title{
Tomada de decisão em bioética clínica: casuística e deliberação moral
}

Elma Zoboli

\section{Resumo}

Nos problemas éticos da clínica é preciso apreciar a situação com o uso de procedimentos sistematizados e organizados para a tomada de decisão, visando diminuir as áreas de incerteza caraterísticas dos conflitos de valores e deveres descobertos na clínica e chegar a resoluções práticas, prudentes e responsáveis. Há vários procedimentos para a tomada de decisão em bioética clínica. $O$ artigo apresenta a casuística e a deliberação. O objetivo é descrever os métodos a partir de publicações de seus propositores. Ambos os procedimentos têm início com a compreensão do caso clínico, considerando nas resoluções as circunstâncias e peculiaridades de cada situação sem perder de vista a imagem-objetivo dos deveres éticos.

Palavras-chave: Bioética. Tomada de decisões. Ética clínica. Comissão de ética. Análise ética.

\section{Resumen}

\section{Toma de decisiones en bioética clínica: casuística y deliberación moral}

En los problemas éticos de la clínica es necesario evaluar la situación con el uso de procedimientos sistematizados y organizados para la toma de decisión, con el fin de disminuir las áreas de incertidumbre típicas de los conflictos de valores y deberes descubiertos en la clínica y llegar a resoluciones prácticas, prudentes y responsables. Existen varios procedimientos para la toma de decisión en bioética clínica. El artículo presenta la casuística y la deliberación. El objetivo es describir los métodos desde las publicaciones de sus proponentes. Ambos procedimientos comienzan con la comprensión del caso clínico, considerando en las resoluciones las circunstancias y particularidades de cada situación, sin perder de vista la imagen objetivo de los deberes éticos. Palabras-clave: Bioética. Toma de decisiones. Ética clínica. Comités de ética. Análisis ético.

\begin{abstract}
Decision making in clinical bioethics: casuistry and moral deliberation

In the ethical problems in clinics it is required to appreciate the situation through the use of organized and systematized procedures to assess the situation for decision-making, in order to decrease the typical uncertainty areas of the conflicts of values and duties found in clinics and to reach practical, wise and responsible resolutions. There are several procedures for decision making in clinical bioethics. The article presents the casuistry and deliberation. The aim is to describe the methods based on the publications of its proponents. Both procedures begin with the understanding of the clinical case and consider in the proposed resolution the circumstances and peculiarities of each situation without losing sight of the objective image of ethical duties. Key words: Bioethics. Decision making. Ethics, clinical. Ethics committee. Ethical analysis.
\end{abstract}

Livre-docente elma@usp.br - Universidade de São Paulo, São Paulo/SP, Brasil.

\section{Correspondência}

Universidade de São Paulo, Departamento de Enfermagem em Saúde Coletiva. Av. Dr. Enéas de Carvalho Aguiar, 419, Cerqueira César CEP 05403-000. São Paulo/SP, Brasil.

Declara não haver conflito de interesse. 
A habilidade de tomar decisões nos problemas éticos é essencial para a excelência profissional e para a qualidade da atenção à saúde. Só é excelente a assistência que alia exatidão técnica e responsabilidade na tomada de decisão ética. Os juízos éticos, como os clínicos, não podem desconsiderar as condições reais e circunstâncias concretas de cada contexto.

Nos problemas éticos da clínica não basta apelar para a intuição ou o bom-senso, pois a incerteza é característica dessas situações e suas soluções são prováveis e revisáveis. Assim, o melhor é apreciar a circunstância particular, com o uso de procedimentos sistematizados para a tomada de decisão em ética - os quais auxiliarão os profissionais na apreciação minuciosa das situações, diminuindo as áreas de incerteza e ambiguidade, capacitando-os para decidir de maneira prudente e responsável.

Há vários procedimentos para a tomada de decisão em bioética clínica. Nas mãos de algumas pessoas todos funcionam bem, enquanto com outras nenhum dá certo. Usualmente, essas pessoas são as que aplicam mecanicamente os métodos, sem perceber e considerar a riqueza e complexidade da realidade ${ }^{1}$. Os profissionais têm de escolher o procedimento mais adequado à realidade na qual atuam.

O presente artigo apresenta dois procedimentos para a tomada de decisão em bioética clínica: a casuística e a deliberação. $O$ objetivo é a descrição de ambos a partir de publicações de seus propositores. Caberiam críticas aos métodos, mas este não é o objetivo do artigo.

\section{Casuística}

A casuística analisa os problemas éticos por meio de procedimentos de equacionamento baseados em paradigmas, analogias e opiniões de especialistas sobre a existência e rigor das obrigações morais, em situações particulares. As obrigações enunciam-se como regras e máximas gerais, não universais ou invariáveis, porque asseguram o bem somente nas condições típicas do agente e das circunstâncias da situação em foco ${ }^{2}$.

As raízes da casuística vêm da antiguidade e sua maior difusão ocorreu na era cristã, especialmente entre 1550 e 1650. Esse método não surge como procedimento para resolver problemas éticos. Seu uso inicia-se entre 1000 e 1200, quando a urbanização provoca mudanças sociais, econômicas, políticas e institucionais que trazem à tona novos casos de consciência. A casuística, então, torna-se muito usada na avaliação conjunta de princípios éticos e detalhes desses casos.

Em 1988, Albert Jonsen e Stephen Toulmin propõem a validez da casuística para a discussão de problemas éticos na clínica, porque entendem que a análise ética típica da casuística e a dos médicos na prática clínica são afins ${ }^{2}$. Caracterizam a casuística: arranjo dos casos por paradigma e analogia; apelo a máximas; análise das circunstâncias; qualificação das opiniões; acúmulo de argumentos e conclusão com a resolução do problema ético ${ }^{2}$.

A casuística ordena os casos em tópicos, por paradigma e analogia. Cada tópico refere-se a um princípio. Os tópicos começam pela definição dos termos-chave e seguem com exemplos de casos, cuja descrição inclui: quem, o que, onde, quando, por que, como e por quais meios. O primeiro caso do tópico exemplifica o desvio mais óbvio, ou seja, ilustra uma violação extrema do princípio. Este caso emblemático é o "paradigma". Os demais, por analogia, afastam-se do paradigma ao introduzir combinações de circunstâncias que tornam a afronta menos aparente.

Nos casos não paradigmáticos, as conclusões são prováveis e não apodíticas, pois não há um único princípio que guie a solução do problema ético. $O$ gradiente de probabilidade das conclusões baseia-se na acumulação de justificativas, motivos e opiniões que corroboram a conclusão, e não na validade lógica ou consistência do argumento. A análise do caso encerra-se com uma solução e um conselho quanto à licitude ou permissibilidade para se agir de um ou outro modo. Nas resoluções há alertas: nessas circunstâncias, dadas essas condições, você pode com razoável segurança agir de tal e tal modo ou fazendo dessa forma, você não agirá precipitada ou imprudentemente e somente pode estar em boa consciência ${ }^{2}$.

Na casuística, a habilidade para reconhecer detalhes e características relevantes do caso é o que mais importa para a resolução dos problemas éticos. Pesa mais a capacidade de reconhecer as circunstâncias da ação e condições do agente do que o domínio prévio dos princípios, conceituações e axiomas. Esses são referidos à medida que surgem na discussão dos casos, pois, na casuística, apreciam-se as regras e princípios morais no contexto específico e circunstâncias reais dos casos - e não em discussões abstratas. Isso não significa que os profissionais não precisem ter noções comuns de ética, das normas de comportamento e atitudes aceitas ou indicadas nos diversos tipos de situação. É preciso que se familiarizem com a literatura sobre ética e sejam competentes na aplicação do método de análise da casuística ${ }^{2}$. 
O entendimento ético depende do reconhecimento dos paradigmas de bem e mal, certo e errado, como nos casos típicos de justiça ou injustiça, crueldade ou gentileza, dizer a verdade ou mentir, cujos méritos e atitudes aceitas estão bem definidos. O conhecimento ético, mais que aceitar proposições universais, é a habilidade de operar o discernimento ético com um olhar para considerações sutis e menos evidentes que podem ser cruciais na concretização das regras e princípios nas situações. A competência ética é a aplicação do discernimento e conhecimento das noções comuns de ética em casos novos.

\section{Casuística na clínica}

$\mathrm{Na}$ aplicação do método casuístico analisa-se o caso clínico descoberto como problema ético em função dos tópicos: indicações médicas; preferências do doente; qualidade de vida e aspectos conjunturais - motivo pelo qual esse procedimento é também conhecido como método das quatro caixas.

Os tópicos são o caminho sistematizado para a identificação, análise e resolução dos problemas éticos na clínica. A análise ética segue a revisão ordenada dos tópicos, ou seja, a apreciação dos casos sempre se inicia pelas indicações médicas, seguida das preferências do doente, qualidade de vida e termina com os aspectos conjunturais. Esse procedimento permite a esquematização dos fatos éticos relevantes no caso e a avaliação da necessidade de se obter mais informação antes do debate para a solução do problema ético.

O tópico 'indicações médicas' refere-se às condições clínicas e intervenções terapêuticas indicadas para o paciente. $O$ primeiro passo na avaliação ética do caso é a distinção clara dos possíveis benefícios da intervenção, a partir da exposição dos fatos clínicos. A análise do caso inicia-se pela pergunta quais as indicações médicas para o caso? e nunca por questionamentos acerca dos direitos do paciente recusar o tratamento ${ }^{3}$.

A adequada compreensão e análise dos problemas éticos requerem cuidadosa apresentação do caso clínico com queixas, estado do paciente, natureza do agravo, diagnóstico, prognóstico e recursos terapêuticos. A finalidade da apresentação é determinar, no caso, os objetivos que podem ser alcançados com a intervenção médica. Na casuística, os objetivos das ações médicas são: promoção da saúde e prevenção de doenças; alívio dos sintomas, dor e sofrimento; cura da doença; prevenção da morte prematura; melhoria do estado funcional ou manutenção da função residual; educação e aconselhamento do paciente; evitar lesões ao paciente durante o tratamento ${ }^{3}$.

Muitas vezes, os problemas éticos decorrem da falta de clareza quanto aos objetivos da intervenção ou da aparente incompatibilidade entre eles. Por isso, a análise do caso tem início pela avaliação realista dos objetivos das indicações médicas, claramente apresentadas para que a equipe, os pacientes e a família compreendam as opções disponíveis na situação. Só após esclarecer as possibilidades de intervenção passa-se para os demais tópicos.

As indicações médicas são apresentadas ao paciente, que decidirá sobre elas segundo sua preferência. A escolha livre e esclarecida do paciente tem importância ética, legal, clínica e psicológica, pois suas preferências integram o núcleo da relação clínica. O paciente opta a partir das indicações e preferências. O conhecimento das preferências do paciente é essencial na ação médica, pois a cooperação e satisfação com a intervenção indicada dependem, em grande medida, do quanto esta vai ao encontro das necessidades, opções e valores do doente.

Considera-se a qualidade de vida do paciente antes da doença, com ou sem tratamento, estimando-se o nível desejável, como atingi-lo e os riscos e benefícios. Os agravos diminuem a qualidade de vida real ou potencial das pessoas e os objetivos fundamentais da intervenção médica são a recuperação, manutenção ou melhoria deste patamar. Não se trata apenas de balanço risco-benefício numa apreciação mais imediata das implicações da recusa ou aceitação do tratamento; as considerações acerca da qualidade de vida analisam as consequências para a vida do paciente, a longo prazo ${ }^{3}$.

O tópico da qualidade de vida é o mais delicado, haja vista exigir análise rigorosa, cuidadosa e atenção para não incorrer em distorções ou preconceitos. Assim, é importante observar: quem faz a avaliação; com que critérios a faz e que tipo de decisão clínica pode ser justificada com base nos juízos sobre qualidade de vida.

Os aspectos conjunturais são as circunstâncias sociais, legais e institucionais envolvidas no caso, ou seja, o contexto - o que faz com que este tópico seja também denominado 'aspectos contextuais'. Nessa etapa precisam ser ponderados, dentre outros, os objetivos dos profissionais; padrões da boa prática; costumes da comunidade; regras legais; políticas de saúde; estruturação e condições dos planos e seguros privados de saúde; diretrizes para pesquisa biomédica; formação dos profissionais de saúde; 
considerações econômicas; credos religiosos; nível educacional da população. As condições contextuais influenciam a assistência médica e esta, por sua vez, afeta o contexto, pois as decisões tomadas em cada caso têm impacto psicológico, emocional, econômico, legal, científico, educacional ou religioso sobre terceiros ou instituições ${ }^{3}$.

A crescente mediação da relação clínica pelos seguros, planos de saúde e políticas públicas tornam os aspectos contextuais cruciais, ou decisivos, para a resolução do caso. Não há regra geral sobre a prioridade dos aspectos conjunturais, mas considera-se que não podem ser priorizados em detrimento das indicações médicas, preferências do paciente ou qualidade de vida, nesta ordem. Para que os aspectos conjunturais tenham peso decisivo na tomada de decisão é preciso que o alcance dos objetivos da intervenção médica seja duvidoso; as preferências do paciente sejam desconhecidas; a qualidade de vida do paciente seja mínima; o aspecto contextual em questão seja específico, nitidamente lesivo para terceiros e a decisão traga alívio para essa lesão ${ }^{3}$. Para cada tópico há perguntas norteadoras das discussões e análise do caso, tal como se observa nas tabelas 1 e 2 , a seguir ${ }^{3}$ :

Tabela 1. Questionamentos sobre indicações médicas e preferências do doente para análise do caso

\begin{tabular}{|c|c|}
\hline Indicações médicas & Preferências do paciente \\
\hline $\begin{array}{l}\text { 1. Qual o problema do paciente? História? } \\
\text { Diagnóstico? Prognóstico? } \\
\text { 2. O problema é agudo? Crônico? Crítico? } \\
\text { Emergência? Reversível? } \\
\text { 3. Quais os objetivos do tratamento? } \\
\text { 4. Qual a possibilidade de sucesso? } \\
\text { 5. Quais os planos se a terapêutica falhar? } \\
\text { 6. Como o paciente se beneficiará dos cuidados } \\
\text { prestados pela equipe? } \\
\text { 7. Como os danos podem ser evitados? }\end{array}$ & $\begin{array}{l}\text { 1. O que o paciente expressou sobre suas } \\
\text { preferências no tratamento? } \\
\text { 2. O paciente foi informado sobre benefícios e } \\
\text { riscos? Compreendeu as informações? Deu seu } \\
\text { consentimento? } \\
\text { 3. O paciente está mentalmente capaz? Tem } \\
\text { competência legal? Há indícios de outro tipo } \\
\text { que sugerem incapacidade para decidir? } \\
\text { 4. O paciente expressou antecipadamente suas } \\
\text { preferências? } \\
\text { 5. Quem é o representante do paciente se } \\
\text { este estiver incapacitado para decidir? O } \\
\text { representante segue regras apropriadas para a } \\
\text { decisão substitutiva? } \\
\text { O paciente reluta contra o tratamento? É } \\
\text { incapaz de cooperar? Por quê? } \\
\text { 7. Respeitaram-se os direitos de escolha do } \\
\text { paciente em sua extensão ética e legal? }\end{array}$ \\
\hline
\end{tabular}

Tabela 2. Questionamentos sobre qualidade de vida e aspectos conjunturais para análise do caso

\begin{tabular}{|c|c|}
\hline Qualidade de vida & Aspectos conjunturais \\
\hline $\begin{array}{l}\text { 1. Quais as perspectivas de retorno do paciente a } \\
\text { sua vida usual, com e sem tratamento? } \\
\text { 2. Há predisposições que prejudicam a avaliação } \\
\text { da qualidade de vida do paciente? } \\
\text { 3. Que déficit físico, mental e social o paciente } \\
\text { pode sofrer se o tratamento for bem-sucedido? } \\
\text { 4. A qualidade de vida presente ou futura faz com } \\
\text { que o paciente não queira mais viver? } \\
\text { 5. Como o paciente argumenta a renúncia ao } \\
\text { tratamento? Há encadeamento lógico na } \\
\text { apresentação dos argumentos? } \\
\text { 6. Quais as possibilidades e planos para cuidados } \\
\text { paliativos e de conforto? }\end{array}$ & $\begin{array}{l}\text { 1. Há assuntos familiares influenciando } \\
\text { indevidamente as decisões terapêuticas? } \\
\text { 2. Há problemas dos profissionais de saúde } \\
\text { influenciando as decisões terapêuticas? } \\
\text { 3. Há interferência desmedida de fatores } \\
\text { econômicos ou sociais? } \\
\text { 4. Há fatores religiosos ou culturais pesando nas } \\
\text { escolhas? } \\
\text { 5. Há justificação para a violação do segredo } \\
\text { 6. Hédico? } \\
\text { 7. Quais problemas de alocação de recursos? } \\
\text { 8. terapêuticas? } \\
\text { 9. Há caso envolve pesquisa? Ensino? } \\
\text { profissionais de saúde? }\end{array}$ \\
\hline
\end{tabular}

Após percorrer as quatro caixas dos tópicos, há outras questões por responder: qual a questão ética no caso?; Onde está o conflito?; O caso é parecido com outros já encontrados?; O que se conhece sobre outros casos similares a esse?; Há precedentes claros?; É um caso paradigmático?; Em que medida o caso se aproxima ou difere do paradigmático?; $O$ distanciamento ou proximidade do caso paradig- 
mático é importante para a análise ética?; Em que medida a resolução de outros casos dependerá do presente ${ }^{3}$. 0 caminho de análise da casuística permite identificar o problema ético do caso e chegar a uma solução prática na tomada de decisão.

\section{Deliberação}

A deliberação de problemas éticos é a consideração dos valores e deveres intervenientes nos fatos concretos a fim de manejar a situação de conflito moral, de maneira razoável e prudente, por meio de discussões e decisões feitas no diálogo interpessoal. Visa soluções prudentes e não a decisão ideal, certa ou que maximiza resultados. Isto porque a racionalidade da deliberação não é idealista, pragmática ou utilitarista, mas crítico-hermenêutica ${ }^{1,4}$. Neste artigo, apresenta-se a proposta de Diego Gracia para deliberação em bioética clínica.

\section{Deliberação moral}

A deliberação é itinerário sistematizado e contextualizado de análise dos problemas éticos para encontrar soluções concretas, dentre alternativas prudentes. Essa análise não é abstrata, mas considera as circunstâncias do ato e as consequências previsíveis. A meta da deliberação são cursos de ação prudentes. Na bioética clínica, a prudência se expressa na capacidade de valorar o que está envolvido no caso, com vistas a decisões razoáveis.

Na deliberação, não se tratam as questões éticas como 'dilemas', confrontando argumentos 'pró' e 'contra' para chegar ao curso com maior probabilidade de ser o correto. A redução da ética a cálculos de probabilidade é incompativel com a deliberação ${ }^{5}$. $\mathrm{Na}$ deliberação, os profissionais pensam conjuntamente; compartilham suas percepções, ou seja, põem em diálogo diferentes sentidos morais. As diferentes perspectivas da realidade são importantes para aprimorar o sentido moral, pois este é coletivo e não só individual ${ }^{6}$. $O$ procedimento deliberativo é um recurso para ajudar a ordenação das discussões em torno de problemas éticos, por meio de passos sequenciais ${ }^{6}$.

Na bioética clínica, 'problema ético' é um caso em que concorrem valores e deveres igualmente obrigatórios e os profissionais não sabem como agir. O problema ético é descoberto no caso como um conflito de valores. Há casos clínicos que não trazem dificuldades aos profissionais, pois a decisão a tomar é clara. Mas, há outros conflitivos, contraditórios, ou seja, o profissional os vê como problemas éticos. Quando isso acontece, tem "paralisia de sentido", não sabe o que fazer ou como agir, necessitando auxílio, pois algo "martela" sua consciência moral ${ }^{6}$.

Os problemas éticos têm saídas morais, cursos de ação, ou seja, as possíveis soluções para o caso. Estas são sempre mais que duas - daí falar-se em problemas éticos e não em dilemas. As saídas possíveis formam um leque, em cujos extremos estão as soluções que realizam um dos valores em conflito e aniquilam o outro. No espaço entre os extremos opostos, ficam saídas prudentes que concretizam ao máximo os valores em conflito ou os lesam o menos possível ${ }^{6}$.

Por exemplo, quando um paciente recusa a transfusão de sangue por motivos religiosos, de pronto a equipe percebe as duas saídas extremas: 'fazer a transfusão à força para evitar a morte do paciente' e 'respeitar sua decisão e deixá-lo morrer'. Essas saídas extremas não são prudentes, pois aniquilam um valor para salvar outro. De um lado, estão os valores 'saúde' e 'vida', pelos quais os profissionais de saúde costumam optar. No outro polo do conflito, está o 'respeito à vontade do paciente'. A opção por salvar os valores 'vida' e 'saúde', fazendo a transfusão à força (ainda que às escondidas do próprio paciente), lesa totalmente o valor 'respeito à vontade do paciente'. A escolha pelo 'respeito à vontade do paciente', não realizando a transfusão, lesa 'vida' e 'saúde', o que costuma ser bastante angustiante para os profissionais. Entre essas soluções extremas há cursos de ação intermédios, que realizam ao máximo, ou lesam o menos possível, os valores em conflito (vida, saúde e respeito à vontade do paciente). Dentre os cursos intermédios, estarão as soluções prudentes, ou cursos ótimos. Esses podem ser mais de um, igualmente prudentes ${ }^{6}$.

\section{Fatos, valores e deveres na deliberação}

O encadeamento de fatos, valores e deveres envolvidos nos problemas éticos levam aos juízos morais. A ética envolve esses três aspectos da realidade: os fatos, orientados pela lógica cognitiva; a valoração, decorrente da estimação e os deveres, que são a obrigação moral de concretizar os valores na situação.

Fato é todo dado de percepção; algo objetivo, contundente, impositivo, observável por qualquer um. Aos fatos correspondem os juízos descritivos, ou juízos de fato, isto é, a reprodução do dado perceptível observado na realidade, por exemplo: 'o fêmur está fraturado' ou 'a manhã está chuvosa'. Os juízos de valor expressam a estimação acerca da percepção, por exemplo: 'tal ação é injusta'; 'o que 
fizeram para o paciente é desumano'; 'a manhã está bela'. Os fatos se percebem e os valores se estimam. O juízo moral inicia-se com os juízos de fato, pois permitem aprofundar o conhecimento da realidade. Porém, os fatos são só um dos âmbitos da deliberação. Delibera-se sobre fatos, valores e deveres ${ }^{7}$.

A tudo que se percebe, necessariamente, atribui-se valor. Não há fatos puros, pois eles sempre carregam junto os valores. Esses não são dados concretos da percepção e não podem ser vistos ou tocados. Fatos e valores são âmbitos distintos, mas relacionados, da realidade. As ações estão no âmbito dos fatos; as motivações e justificativas para as ações são os valores. Esses, então, ancoram-se nos fatos e sofrem influências sociais, históricas e culturais. Ou seja, os valores são, ao mesmo tempo, intuídos individualmente e construídos socialmente ${ }^{4}$. Aos valores correspondem juízos valorativos, que se apoiam nos juízos de fato ${ }^{7}$.

Como os valores têm componentes intuídos individualmente, há o risco do subjetivismo. Entretanto, não se trata só de preferências pessoais, porque algumas dessas são social e politicamente contestáveis. $\mathrm{E}$, ainda, há valores que devem ser assumidos por todos a fim de que a realidade torne-se mais apropriada a uma vivência compatível com a dignidade humana: liberdade, solidariedade e beleza ${ }^{8}$.

Os deveres são o aspecto formal da obrigação moral. O conteúdo dos deveres advém dos valores. O dever admite dois níveis: o 'dever ideal' ou 'deveria' e o 'dever realizável' ou 'deve'. No equacionamento ético ponderam-se as proposições ideais e categóricas do âmbito do 'deveria' e as possíveis e hipotéticas do nível do 'deve'. A obrigação moral é concretizar o 'deveria' partindo-se do 'deve'. Na deliberação, considera-se o âmbito do 'deveria', que é o momento de idealidade, da imagem-objetivo, para se chegar ao nível 'deve', ou seja, do que é possível concretizar dos valores em conflito ${ }^{4}$. As decisões prudentes, tomadas com 'responsabilidade moral', propiciam a articulação entre 'deveria' e 'deve' 7 .

Quando os deveres entram em conflito e os profissionais não sabem como agir para concretizar os valores na sua prática clínica, se olharem só para o 'mundo ideal' não conseguirão chegar ao 'devo' possível em cada caso. A deliberação facilita esse trajeto. O procedimento deliberativo de Diego Gracia foi proposto para comissões de bioética, mas pode ser utilizado em reuniões de equipes multiprofissionais, nas decisões individuais ou na mediação dos conflitos éticos entre pacientes, familiares e profissionais. Neste artigo, usa-se a aplicação nas comissões de bioética como guia para descrever o procedimento.

\section{O procedimento deliberativo}

O itinerário do processo deliberativo inclui: deliberação sobre os fatos (apresentação do caso e esclarecimento dos fatos); deliberação sobre os valores (identificação dos problemas éticos do caso; indicação do problema ético fundamental e identificação dos valores em conflito); deliberação sobre os deveres (identificação dos cursos de ação extremos, intermédios e ótimo); deliberação sobre as responsabilidades (submissão do curso ótimo às provas de consistência de tempo, publicidade e legalidade) ${ }^{4}$.

\section{Deliberação sobre os fatos}

- Apresentação do caso

O profissional que identificou o caso clínico como problema ético e ficou sem saber o que fazer apresenta-o à comissão de bioética. Conta a história clínica, com ênfase nos aspectos éticos e dados sobre condições sociais, familiares, culturais, educacionais, religiosas e outros que julgar importantes para a compreensão da situação.

Esta fase assemelha-se às sessões clínicas. Entretanto, o foco é o problema ético. Exploram-se detidamente os fatos da história clínica, pois são o suporte dos valores em conflito no caso. A história clínica é o suporte material do problema ético a ser analisado, e deve ser conhecida e entendida para reduzir as áreas de incerteza na deliberação.

- Esclarecimento dos fatos do caso

Após a apresentação do caso, os membros da comissão de bioética esclarecem pontos que ficaram pouco claros ou não foram incluídos, por meio de perguntas ao profissional que apresentou o caso. Para o sucesso do procedimento deliberativo, é fundamental compreender o caso. As falhas em sua compreensão arrastam-se para as demais etapas da deliberação e comprometem a prudência da decisão. Quanto melhor a compreensão do caso, mais fácil reconhecer os recursos disponíveis para propor cursos de ação realizáveis.

\section{Deliberação sobre os valores}

- Identificação dos problemas éticos

Os membros da comissão de bioética listam os problemas morais que percebem no caso. Por serem dificuldades, dúvidas, a melhor maneira de enunciar os problemas éticos é com perguntas. Para facilitar a identificação dos valores em conflito nos problemas, as perguntas devem ter linguagem precisa, clara, sem ambiguidades. 
Devem-se evitar questões binárias: 'O médico deve respeitar a decisão do paciente que recusa a transfusão?'; 'É lícito respeitar a decisão do paciente que recusa a transfusão?' ou 'É ético o profissional respeitar a vontade do paciente que recusa a transfusão?'. Não usar perguntas de cunho legal, jurídico: 'É legal não transfundir um paciente que precise do procedimento e o recusa?' ou 'É legal respeitar a vontade do paciente, ainda que isso possa lhe levar à morte?'. O melhor é formular questões abertas: 'Até onde chega a responsabilidade de um médico diante de um paciente que não quer que lhe façam uma transfusão?'.

Para conferir maior clareza às perguntas, não usar termos polissêmicos como autonomia, beneficência, não maleficência, equidade, integralidade. A 'pergunta-problema' tem de ser formulada segundo a realidade do caso e não de maneira 'genérica', 'padronizada'. Nem todas as perguntas formuladas expressam 'verdadeiros' problemas éticos, ou seja, há algumas que não contêm conflitos de valores. Mas, para diminuir o risco de exclusão dos 'verdadeiros problemas éticos', convém que a lista não seja muito reduzida. Paralelamente, listas extensas tendem à repetição.

- Indicação do problema ético fundamental

É impossível analisar todos os problemas éticos identificados no caso. Motivo pelo qual elege-se um para ser alvo da deliberação. Este é o 'problema ético fundamental'. Usualmente, quem o elege é o profissional que apresentou o caso à comissão de bioética, pois foi quem reconheceu o caso clínico como problema ético.

- Identificação dos valores em conflito

Para avaliar essa questão é preciso, primeiro, verificar se a pergunta escolhida como 'problema moral fundamental' representa, de fato, um conflito de valores. Em caso afirmativo, segue-se o procedimento com a identificação dos valores em conflito. Caso contrário, retoma-se a lista para indicar outro problema ético fundamental.

Um conflito de valores mal definido compromete a sequência do processo deliberativo, pois perde-se a essência do caso. Tal fato implica que a linguagem na identificação dos valores em conflito deve ser clara e precisa, o que requer atenção redobrada pois os valores se expressam com termos abstratos, propícios às imprecisões e com os quais não estamos habituados. Na enunciação dos valores em conflito, deve-se transpor, sem prejuízo da precisão, a linguagem concreta dos problemas para termos mais abstratos.
Para não dispersar a discussão, convém escolher dois, ou no máximo quatro, valores para a deliberação.

\section{Deliberação sobre os deveres}

- Identificação dos cursos de ação extremos

O que é definido como 'curso de ação' refere-se a cada uma das alternativas de solução para o caso. Os valores em conflito estão dispostos em dois polos opostos. A cada polo corresponde um 'curso de ação' extremo, que realiza só um dos valores em conflito e, consequentemente, aniquila o outro. Os cursos extremos são imprudentes e devem ser evitados. Evitar os extremos não é fácil, porque a mente humana pende, 'naturalmente', para os polos ao vislumbrar só duas vias de solução para os problemas éticos.

- Identificação dos cursos de ação intermédios

As saídas morais que ficam entre os polos extremos são os 'cursos de ação intermédios'. Partem dos extremos rumo ao centro, ao 'justo meio', espaço privilegiado da prudência que permite realizar os dois valores em conflito.

- Identificação do curso de ação ótimo

Dentre os 'cursos intermédios' elege-se o 'curso ótimo', ou seja, o que realiza ao máximo, ou prejudica o menos possível, todos os valores envolvidos no conflito. A escolha do 'curso ótimo' requer o exercício delicado e atencioso de comparação das opções. Esse passo do procedimento deliberativo é o momento moral propriamente dito. $O$ 'curso ótimo' será a alternativa mais prudente e responsável para solucionar o problema ético.

\section{Deliberação sobre as responsabilidades}

- Aplicação das provas de consistência

Escolhido o 'curso ótimo', é preciso submetê-lo à comprovação de consistência por meio das provas de legalidade ('essa decisão é legal?'), publicidade ('estaria disposto a defender publicamente a decisão tomada?') e temporalidade ('tomaria a mesma decisão se tivesse mais tempo para decidir?'). Esses critérios visam comprovar a prudência e responsabilidade do 'curso de ação ótimo'.

A prova do tempo é um exercício mental para verificar se a decisão não está sendo precipitada, impulsiva ou excessivamente movida pelas emoções. A prova da legalidade lembra que há decisões morais que são ilegais. A prova da publicidade visa verificar se a decisão goza de argumentação pública, responsável e justa. A decisão mais prudente é a que passa pelas três provas. 


\section{- Decisão final}

Esse passo cabe ao profissional que apresentou o caso à comissão de bioética. A comissão indica caminhos prudentes para solucionar o problema ético, mas são as pessoas envolvidas no caso que os efetivam após tomarem sua decisão de seguir ou não o resultado da deliberação.

\section{Considerações finais}

Face ao pluralismo moral, a deliberação torna-se importante instrumental da bioética clínica. Os profissionais de saúde precisam desenvolver hábitos, habi- lidades e competências deliberativas para aprimorar a qualidade da atenção à saúde.

Os métodos apresentados neste artigo, a casuística e a deliberação, iniciam-se com a compreensão do caso clínico. São procedimentos que propiciam decisões concretas, indicando um curso de ação realizável para solucionar o problema ético em foco. Ambos consideram as circunstâncias e peculiaridades da situação sem perder de vista a imagem-objetivo das obrigações éticas. São formas sistematizadas para organizar a discussão nos conflitos de valores e deveres descobertos na clínica e diminuir as áreas de incerteza na tomada de decisão ética.

\section{Referências}

1. Guillén DG. La deliberación moral: el papel de las metodologías en ética clínica. Madrid: Universidad Complutense; 2009.

2. Jonsen AR, Toulmin SE. The abuse of casuistry: a history of moral reasoning. Bekerley: University of California Press; 1988.

3. Jonsen AR, Siegler M, Winslade WJ. Ética clínica. $4^{a}$ ed. Lisboa: McGraw-Hill; 1999.

4. Zoboli ELCP. Deliberação: leque de possibilidades para compreender os conflitos de valores na prática clínica da atenção básica [tese]. São Paulo: USP; 2010.

5. Gracia D. Moral deliberation: the role of methodologies in clinical ethics. Med Health Care Philos. 2001;4(3):223-32.

6. Pose C. Lo bueno y lo mejor: introducción a la bioética médica. Madrid: Editorial Triacastela; 2009.

7. Pose C, Gracia D. Introducción a la bioética: origen, fundamentación y metodo [material didáctico]. Madrid: Universidad Complutense; 2006.

8. Ortis AC. El mundo de los valores: ética mínima e educación. Bogotá: Editorial el Buho; 2007.

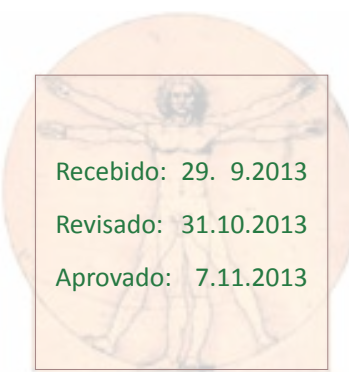

